\title{
Acoustic Phenotypes of an Alpine European Common Frog Population
}

\author{
Miramontes-Sequeiros LC*1, Palanca-Castan $\mathrm{N}^{2}$ and Palanca-Soler \\ $\mathbf{A}^{1}$ \\ ${ }^{1}$ Animal Anatomy Laboratory Foundation, Spain \\ ${ }^{2}$ Neuroscience of Circuits and Systems Laboratory, Chile
}

Research Article

Volume 2 Issue 5

Received Date: September 12, 2019

Published Date: September 19, 2019

DOI: $10.23880 /$ izab-16000175

*Corresponding author: Luz Calia Miramontes Sequeiros, Animal Anatomy Laboratory Foundation, Faculty of Biology, Campus Lagoas-Marcosende, 36310-Vigo, Spain; Email: luz.miramontes@outlook.es

\section{Abstract}

In this work we studied the acoustic variability in the induced release call on wild populations of the European common frog Rana temporaria. We used a computational model to analyze the induced release calls in both sexes. Our analysis detected three different acoustic phenotypes: (a) Non-canonical males comprised a large part of the population and were the main cause of the biased sex ratio (Phenotype 2), since (b) canonical males (Phenotype 1) and (c) canonical females (Phenotype 3) had close to a 1:1 ratio. Phenotype 2 were much more abundant in locations were tadpoles were exposed to high water temperatures during their development, suggesting that a masculinizing effect of temperature is responsible for the biased sex ratio, and a likely origin for "pirate" males which search for newly laid clutches to fertilize not fertilized eggs by the "parental" males.

Keywords: Rana temporaria; Release Call; Acoustic Phenotypes; Water Temperature; Theoretical Solar Radiation

\section{Introduction}

The European Common Frog is the most widespread anuran species of Europe inhabiting all kinds of permanent and temporary waters from northern Spain to subarctic Fennoscandia, and all the way to the Ural mountains in the east [1].

In 1995, the third author, described a morphotype which inhabit the Central Pyrenees designed as Rana temporaria aragonensis which presented morphological differences when compared to Rana temporaria temporaria, such as a wider skull, a lower distance between eyes and a shorter and wider mouth, differences in the femur sinuosity,...Later, Teacher, et al. [2] studied the distribution of the European clades of Rana temporaria and claimed that there were two different clades in the Pyrenees which overlapped our study area in the Central Pyrenees. Taking into account that one of the main factors acting in the call characteristics is the skull dimensions [3].

In 2004, the third author, found behavioral differences in the mating strategies of our study population, where a 


\section{International Journal of Zoology and Animal Biology}

previously unknown reproductive behavior in vertebrates with external fertilization called 'clutch piracy' was described in our study area with a male-female sex ratio 2:1 [4]. This "pirate" males search for recently laid clutches clasping them to fertilize the eggs not yet fertilized by the "parental" male.

It is possible that this longstanding sex imbalance has been exacerbated by male aggression resulting from a lack of available females [5,6]. We have in several occasions observed males attacking and kicking females. In addition, this sex imbalance could be the cause for novel mating strategies such as the clutch piracy previously reported in this population [4]. This kind of extreme environmental masculinization can be dangerous for populations. The combination of unbalanced phenotypical sex ratios, reduction in genetic variability and male aggression are likely to result in drastic population reduction or even extinction [7]. The possible impact of temperature rise on animals with temperaturebased sex determination is not a new idea. It has been observed that even small increases of $1-2 \stackrel{\circ}{ } \mathrm{C}$ in air temperature could have significant effects on the sex ratios of sea turtles, and some authors warned about large, fast temperature rises having very detrimental effects on populations [8]. Some authors Miller, et al. [9] argue that it is possible that dinosaurs had temperature sex determination and that fast climatic change at the Cretaceous-Tertiary boundary was a contributing factor to the collapse of their populations. Lastly, recent studies Mitchell, et al. [10] Grayson, et al. [11] point out that species that show female to male sex reversal at high temperatures such as Sphenodon tuatara could experience severe impact under current predictions for temperature rise. Our data shows that the existence of more intense and frequent high temperature extremes can have a severe effect on isolated populations that show temperature-mediated masculinization. Populations with a sex ratio heavily skewed towards males such as the one reported in this study are at risk of demographic collapse [11].

Although masculinization at high temperatures is wellknown in R. temporaria as well as other amphibians [12], it is unclear exactly how widespread it is. If this is a common phenomenon among amphibians, temperaturemediated demographic collapse could be an important factor in the declines observed in the past years $[13,14]$. This is consistent with the observation that declines have a tendency to occur at higher altitudes [15], as shorter activity periods would delay tadpole metamorphosis to the warmer summer months, as described in our study population.

Our main goal is to find the existence of acoustic phenotypes, in wild environments and not in laboratory, due to the occurrence of both clades of $R$. temporaria in our study area. Indeed, another objective is to acoustically differentiate "pirate" from "parental" males in our population. Lastly, the third objective is to study the effect of temperature during metamorphosis in the acoustic phenotypes.

\section{Material and Methods}

\section{Study Area}

During the summer of 2013 and 2014 we sampled 68 water bodies in an area of $600 \mathrm{~km}^{2}$ located in the Central Pyrenees (Figure1). From which we selected seven sampling sites where we found adult frogs with a snoutvent-length (SVL) between 4.6 and $6.4 \mathrm{~cm}$ (approx. 5 to 6 years old). Three spring and streams located in lowaltitude sampling sites, Aguas Tuertas, Formigal, Surgencias en Acherito (valley), and four glacial lake highaltitude sampling sites, Bachimaña Bajo and Alto, Brazato and Asnos. Both with an average distance higher than 15 $\mathrm{km}$ and large geographical barriers.

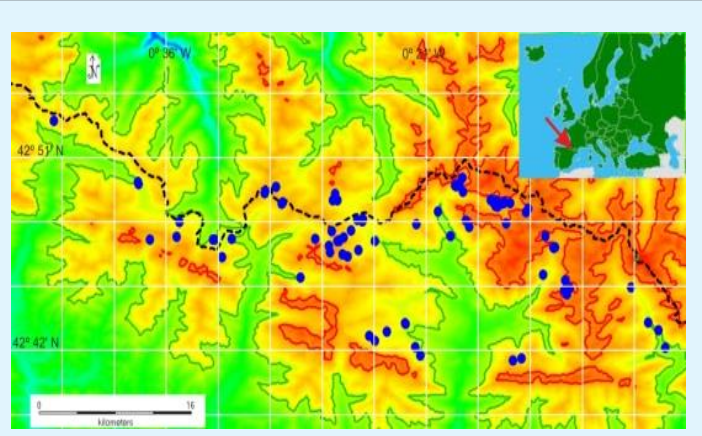

Figure 1: Map of our study area in the Central Spanish Pyrenees (Aragón, Spain) with the sampling sites marked by blue dots. White squares placed every 3 minutes North-West. Green and red level lines represent altitudes at 1600 and $2400 \mathrm{~m}$ a.s.l. respectively. Black dash line is the Spanish-French border.

\section{Animal Sampling}

We sampled a total number of 532 frogs from which only 55 were sexually receptive males and females, 29 in springs and streams and 26 in glacial lakes with altitudes 
ranging from $1600-1700$ and $2200-2300 \mathrm{~m}$ a.s.l. respectively. We identified sex unambiguously using external morphological sexual characters (nuptial pads, size, and white throat in males). These frog populations breeded every year.

In order to avoid the size effect in our samples, we selected the induced release calls of adult frogs with a SVL in a specific range 4.6 to $6.4 \mathrm{~cm}$. The SVL data collected from smaller frogs were not considered for this study.

\section{Sound Data Recordings}

Although other European populations of $R$. temporaria have been described to sing in chorus during the breeding season [16], individuals from both sexes of $R$ temporaria in our alpine study population are known to do not sing in chorus during the breeding season and only emit spontaneous vocalizations when they are underwater, which led us to use induced, above-water release calls for being less complicated to obtain [3].

We recorded induced release calls of individuals from our study population and analyzed them in order to test for the presence of different acoustic phenotypes. Release calls are produced by both male and unreceptive female frogs when grasped by male frogs [17]. This type of vocalization can be easily induced by gently grabbing the frog and results in little to no damage or stress for the animal.

Vocalizations were recorded using a TCD-D8 Portable Digital Audio Tape (Sony Corporation, Tokyo, Japan) a directional microphone (C568B, AKG acoustics, Vienna, Austria) with integrated amplifier and 20-20.000 Hz bandwidth. Sampling rate was $44.1 \mathrm{kHz}$ with a sampling depth of 16 bits.

Our recordings consisted of release calls, which are produced by both male and unreceptive female frogs when clasped by male frogs [18]. This type of call presents sexual dimorphism in the number of pulses, inter-pulse interval, maximum frequency and duration of the call $[19,20]$. This call can also be used to distinguish Neotropical and European toads' species [21,22].

The release call in $R$. temporaria was classified by van Gelder, et al. [23] in function of the amplitude pattern of the pulses. We studied the pulses defined as a "vibrator note" in function of the amplitude pattern of the peaks, which is the main difference with respect to the other bioacoustics amphibian studies (Figure 2) [3]. These pulses with peaks are an inferior fractal order with respect to the entire call.

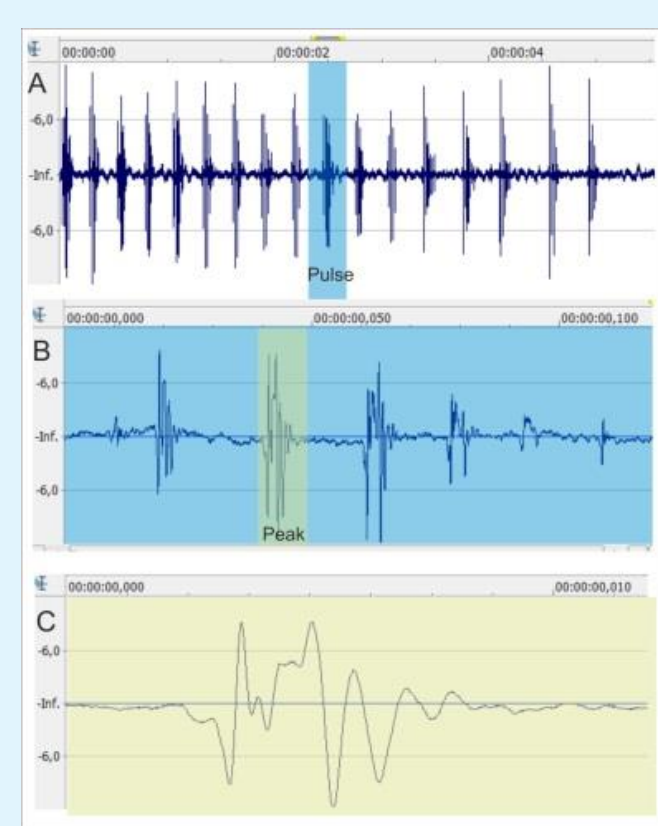

Figure 2: A Oscillogram showing the different pulses of a entire call. B Oscillogram of a specific pulse extracted from the A, showing the different peaks in it. C Oscillogram of a specific peak extracted from B showing its amplitude pattern. These pulses with peaks represent an inferior fractal order with respect to the entire call.

\section{Environmental Data}

We measured the water temperature with a digital thermometer in the majority of the sampling sites during the end of July and the first week of August, under the same climatic conditions, sunny, and between 12 and 14 solar hours.

To be able to extrapolate the water temperatures along the year we calculated the theoretical solar radiation in our sampling sites using the Morgen, et al. [24] for the parallel 50 (close to the study area), which already consider the slopes and shielding effect of slopes. In each sampling site we traced two profiles using the Global Mapper GIS application (Company: DroneMapper) software, one North-South profile and a second WestEast. Afterwards we calculated the profiles angles with the highest slope in the sampling site and its exposition using the GeoGebra International software [25]. 


\section{International Journal of Zoology and Animal Biology}

\section{Data Processing}

For each of our analyzed call pulses (Figure 2) we characterized the following variables that define some of the fundamental characteristics of a vocalization using custom Matlab scripts (MATLAB R2013b 8.2.0.701, Mathwoks, INC) to repeat the analysis of 2152 pulses from the 55 release calls emitted by the 55 adult frogs:

- The first harmonic or fundamental frequency (F0).

- Number of peaks in each pulse (Figure 2).

- A measure of distortion calculated using the thd MATLAB function. The total harmonic distortion is determined from the fundamental frequency and the first five harmonics using a modified periodogram of the same length as the input signal. It is a negative number which shows the frequency modulation, being lower as the modulation increases.

In addition, we added eight other variables corresponding to the location, year, month and day of sampling, snout-vent length (SVL) in $\mathrm{cm}$, a consecutive number of an analyzed pulse within the call and sex of the individual as determined by morphological characteristics.

Using the IBM SPSS Statistics 19.0 (SPSS, Inc., Chicago, IL) statistical package for Windows, we carried out a hierarchical cluster analysis (HCA) using the F0, Number of peaks in each pulse and Distortion variables clustering 2152 pulses into four clusters.

Using each cluster as a grouping variable and the above-mentioned variables as independent variables we performed a discriminant analysis, determining as new clusters the predicted groups for each pulse and using them as a base for the next discriminant analysis. This process was repeated three times until the clusters were fully stabilized, thus optimizing the discrimination, each of these stabilized clusters are called Type of pulse (Figure 3A).
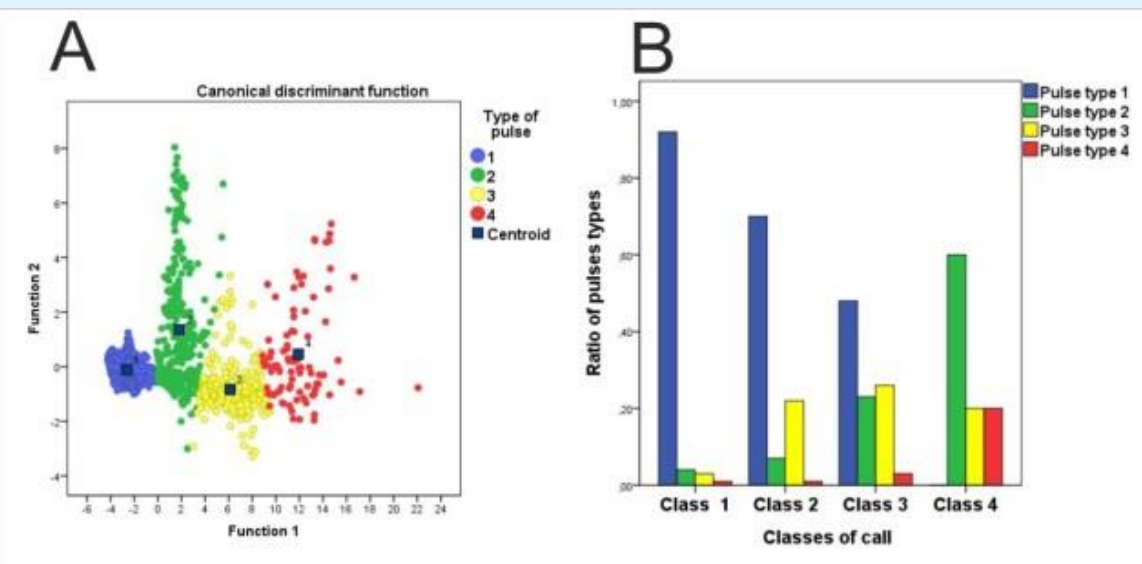

Figure 3A: Results of the discriminant analysis that resulted in the classification of pulses in four types. X and Y axes show the value of Functions 1 and 2, respectively. Cluster centroids are marked by a square and its group number.

3B: Classification of the studied vocalizations in four classes of call according to the proportion of each type of pulse present.

Given the four different types of pulses, each call (one call for frog) was subsequently classified using a cluster analysis taking as variables the ratio of pulses types present within it. We obtained four classes of call (Figure 3B). To measure the strength of these four variables measured we run a nonparametric Kendall's tau-b (Tb) and Spearman's Rho correlations showing the acoustic phenotypes. Afterwards we assigned the morphological frog sex to these resulting acoustic phenotypes separating sampling frogs from glacial lakes and springs and streams.

\section{Results}

\section{Acoustic Phenotypes}

The canonical discriminant analysis (Figure 3A) showed a Wilks' Lambda of 0.037 (Sig. 0.00). The intra class correlations between the discriminant variables and 
the typified canonical discriminant functions showed the higher values function 1 with the F0 ( $\mathrm{r}=0.991)$ and function 2 with the Number of pulses ( $\mathrm{r}=0.961)$. We obtained four types of pulses defined by an oscillogram (column 1), periodogram (column 2) and spectrogram (column 3) of each a representative pulse of each of the four types defined in the study (Figure 4) and their acoustical characteristics are shown in Table 1.

\begin{tabular}{|c|c|c|c|c|}
\hline Pulse type Variables & $\mathbf{1}$ & $\mathbf{2}$ & $\mathbf{3}$ & $\mathbf{4}$ \\
\hline Distortion & -7.25 & -5.7 & -8.98 & -45.9 \\
\hline F0 harmpow (dB) & -14.66 & -3.85 & -19.4 & -1.4 \\
\hline F0 harmfreq (Hz) & 150.19 & 811.8 & 876.2 & 2011.7 \\
\hline Lenght (ms) & 67.61 & 39.63 & 50.89 & 26.37 \\
\hline Number of peaks & 10 & 20 & 2 & 73 \\
\hline Peaks/ms & 0.15 & 0.5 & 0.04 & 2.77 \\
\hline
\end{tabular}

Table 1: Numerical values and identifiers of the example types of pulses shown in Figure 4. Distortion (thd Matlab function), $\mathrm{dB}$ and $\mathrm{Hz}$ of the fundamental frequency (F0), pulse length, number of peaks and peaks per ms.

\section{Types of pulse}
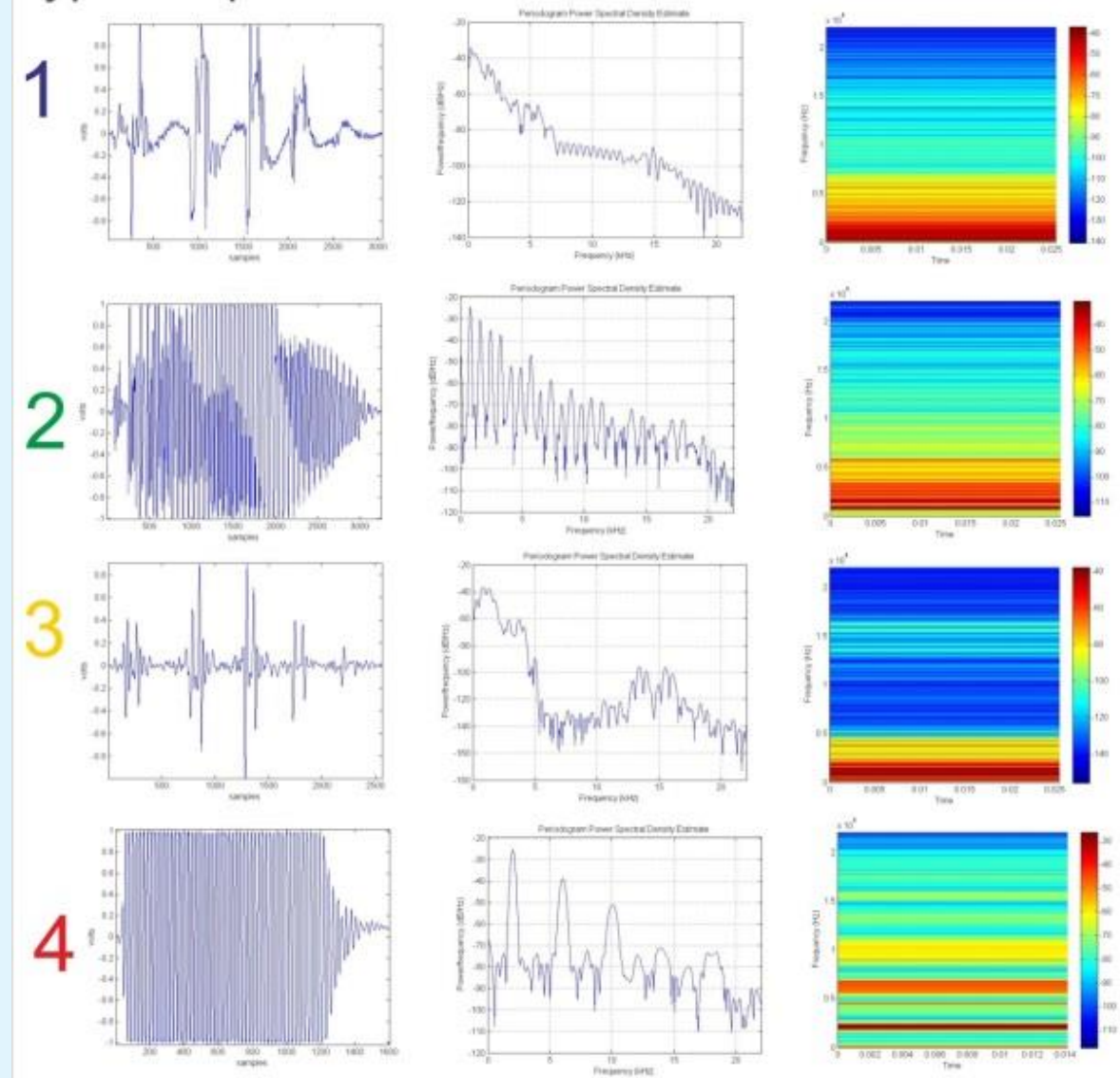

Figure 4: An oscillogram (column 1), periodogram (column 2) and spectrogram (column 3) of each a representative pulse of each of the four types defined in the study. 
Among these four classes of call we found not significant differences between class 2 and 3 (Table 2). Therefore we grouped them together in one class of call, having a final number of three classes of call or acoustic phenotypes.

\begin{tabular}{|c|c|c|c|c|c|}
\hline \multicolumn{2}{|c|}{ Correlations $N=4$ (Ratio of pulses type) } & \multicolumn{4}{|c|}{ Tau_b de Kendall } \\
\hline \multicolumn{2}{|c|}{ Clases of call } & Class 1 & Class 2 & Class 3 & Class 4 \\
\hline \multirow{2}{*}{ Class 1} & C. of $\mathrm{c}$. & 1 & 0.667 & 0.667 & -0.183 \\
\hline & Sig. bilateral & & 0.174 & 0.174 & 0.718 \\
\hline \multirow{2}{*}{ Class 2} & C. of c. & 0.8 & 1 & $1,000^{*}$ & -0.548 \\
\hline & Sig. bilateral & 0.2 & & 0.01 & 0.279 \\
\hline \multirow{2}{*}{ Class 3} & C. of c. & 0.8 & $1,000^{*}$ & 1 & -0.548 \\
\hline & Sig. bilateral & 0.2 & 0.01 & & 0.279 \\
\hline \multirow{3}{*}{ Class 4} & C. of $\mathrm{c}$. & -0.316 & -0.632 & -0.632 & 1 \\
\hline & Sig. bilateral & 0.684 & 0.368 & 0.368 & \\
\hline & & \multicolumn{4}{|c|}{ Rho de Spearman } \\
\hline
\end{tabular}

Table 2: Results of the correlation tests between each pair of the groups created according to the proportions of pulse types. The upper part of the table shows the results of Kendall's Tau_b, while the lower part shows the results of Spearman's Rho.

When we assigned the morphological frog sex to the three resulting acoustic phenotypes we found that the frog males present two acoustical phenotypes both in the glacial lakes and springs and streams, whereas frog females presented one (Table 3).

\begin{tabular}{|c|c|c|c|c|c|c|c|c|c|c|}
\hline \multirow[b]{2}{*}{$\begin{array}{l}\text { Sampling } \\
\text { sites }\end{array}$} & \multirow[b]{2}{*}{$\begin{array}{c}\text { Acoustic } \\
\text { phenotype }\end{array}$} & \multirow[b]{2}{*}{ Frog sex } & \multirow[b]{2}{*}{$\begin{array}{c}\text { Frog } \\
\text { number }\end{array}$} & \multicolumn{2}{|l|}{ SVL } & \multirow[b]{2}{*}{$\begin{array}{l}\text { Altitude } \\
\text { (m a.s.l.) }\end{array}$} & \multicolumn{2}{|r|}{ Ratio } & \multirow{2}{*}{\begin{tabular}{|c|} 
Theoretical \\
solar \\
radiation \\
(Kcal/cm2 \\
year)
\end{tabular}} & \multirow[b]{2}{*}{$\begin{array}{c}\text { Water } \\
\text { temperature } \\
\left({ }^{\circ} \mathrm{C}\right)\end{array}$} \\
\hline & & & & Mean $(\mathrm{cm})$ & S.D. & & $\begin{array}{c}\text { P2/ } \\
\text { P1 }\end{array}$ & $\begin{array}{c}\mathrm{M}: \mathrm{F} \\
(\mathrm{P} 1+\mathrm{P} 2 / \mathrm{P} \\
\text { 3) }\end{array}$ & & \\
\hline \multirow{4}{*}{$\begin{array}{l}\text { Springs and } \\
\text { streams }\end{array}$} & P1 & $\mathrm{M}$ & 10 & 6.1 & \pm 0.7 & 1636- & \multirow{4}{*}{ 1:01 } & \multirow{4}{*}{$2.6: 1$} & \multirow{4}{*}{10 to 65} & \multirow{4}{*}{9 to 13} \\
\hline & P2 & M & 11 & 6.4 & \pm 0.5 & 1709 & & & & \\
\hline & P3 & $\mathrm{F}$ & 8 & 5.9 & \pm 1.2 & & & & & \\
\hline & Total & & 29 & & & & & & & \\
\hline \multirow{4}{*}{ Glacial lakes } & $\mathrm{P} 1$ & $\mathrm{M}$ & 4 & 5.8 & \pm 1.0 & 2213 & \multirow{4}{*}{$4.25: 1$} & \multirow{4}{*}{$4.2: 1$} & \multirow{4}{*}{76 to 100} & \multirow{4}{*}{20 to 32} \\
\hline & $\mathrm{P} 2$ & $M$ & 17 & 5.7 & \pm 0.7 & -2286 & & & & \\
\hline & P3 & $F$ & 5 & 4.6 & \pm 0.3 & & & & & \\
\hline & Total & & 26 & & & & & & & \\
\hline
\end{tabular}

Table 3: Breakdown of the samples taken from glacial lakes and from springs and streams, noting the number of individuals of each acoustic phenotype, morphologic frog sex, frog number, average and standard deviation of snout-vent length (SVL) in cm, sampling altitude interval, ratios of non-canonical males (P2 assimilated to "pirate" males) to canonical (P1 assimilated to "parental" males) and of males (P1+P2) to females (P3), theoretical solar radiation in $\mathrm{Kcal} / \mathrm{cm} 2$ year and water temperature in ${ }^{\circ} \mathrm{C}$ taken during the last week of July and the first week of August from 12 to 14 solar hours under sunny climatic conditions.

\section{Environmental Variables}

We compared the theoretical solar radiation and water temperature among our sampling sites which were gathered in two groups, low-and high-altitude, springs and streams and glacial lakes respectively (Table 3). Both the theoretical solar radiation $\left(\mathrm{kcal} / \mathrm{cm}^{2}\right)$ and the water temperature $\left({ }^{\circ} \mathrm{C}\right)$ in glacial lakes had higher values than those found in springs and streams (Figure 5). 


\section{International Journal of Zoology and Animal Biology}

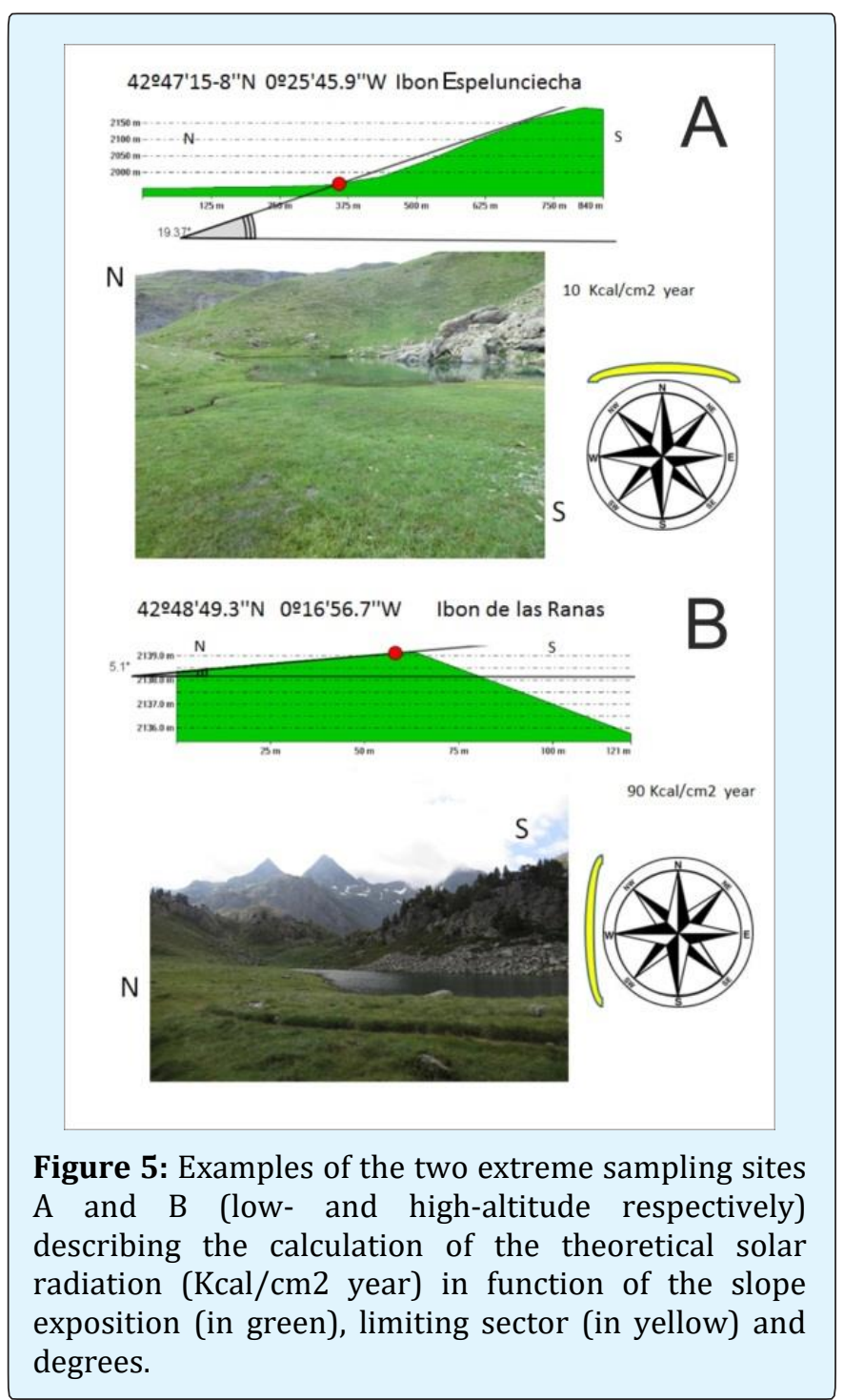

\section{Acoustic Phenotypes and Environmental Variables}

When comparing the acoustic phenotypes occurrence between both high- and low-altitude we found the phenotype 1 and 2 (P1 and P2 respectively), corresponding to males, showed a ratio 1:1 (P2/P1) in low-altitude and low theoretical solar radiation and water temperature, whereas they had a 4.25:1 (P2/P1) ratio in high-altitude, high theoretical solar radiation and water temperature. The acoustic phenotypes male-female ratio (P1+P2/P3) increased with altitude, theoretical solar radiation and water temperature, from 2.6:1 to 4.2:1 (Table 3).

\section{Discussion}

Our results showed the existence of three acoustic phenotypes recognizable in the release call. The phenotype 1 and 2 were assigned to morphological male adult frogs, and phenotype 3 to morphological female adult frogs. In addition, the phenotype 1 ("parental" males) consisted of the more canonical males, which exhibit their vocal sacs when singing under-water, which emitted almost exclusively, type 1 pulses, showing a very tight and consistent clustering as expected from a trait subject to heavy selective pressure. The phenotype 2 ("pirate" males) corresponded to individuals with malelike vocalizations but with different degrees of divergence from the canonical vocalization and closer to females, which did not exhibit the vocal sacs when singing underwater like females did. Intermediate individuals outnumbered both canonical males and canonical females, and they were much more abundant among individual sampled from high-temperature glacial lakes than from those taken from springs and streams. Given the presence of this intermediate individuals, along with the high male-to-female ratio observed in our study populations and the existence of "pirate" males that are unable or unwilling to attract females but fertilize clutches we propose that these high-mountain populations are suffering from a masculinizing effect of temperature that is exacerbated among those frogs that go through metamorphosis in high-temperature waters.

Any normal population with exclusively genetic sex determination (like endotherm vertebrates) is expected to have close to a 1:1 male-to-female ratio, while the studied population has an overall 4:1 male-to-female ratio which is supported by deviations of sex ratios previously described in R. temporaria [26]. The mechanisms of sex determination in $R$. temporaria remain unclear. Their sex chromosomes are weakly differentiated [27,28]. And although some sex-linked genetic markers have been found Matsuba, et al. [29] others have found families and subpopulations in which males and females are genetically identical [30]. Other recent studies have found large differences in the extent to which sex is linked to genetic markers in different families and regional populations [31].

As part of the ongoing climate change, temperatures have been rising in the Central Pyrenees [32,33] and episodes of unusually high temperatures have become more frequent and [34]. Our study area consists of highmountain valleys that are mostly free of organic contaminants, and the only noticeable human impact 


\section{International Journal of Zoology and Animal Biology}

comes from hikers and the occasional camper. Therefore, it is unlikely that any imbalance on the sex ratios is the consequence of environmental contaminants. Moreover, as a consequence the short activity period in high mountain and the presence of snow during spring, frog reproduction occurs in June and tadpole metamorphosis in August. Juveniles are thus exposed to the highest peak water temperatures of the year. Our results might suggest that the reduction on the proportion of females in our study populations is the result of rising temperatures having an increasingly masculinizing effect on developing frogs. This is reinforced by the presence of a much larger imbalance among those frogs that reproduce in lakes, which migth have been exposed to water temperatures of up to $32^{\circ} \mathrm{C}$. This masculinization effect would result in males with slight anatomical and behavioral differences when compared to more canonical males, which would explain the differences in patterns and unusual behaviors such as male "piracy" [4].

\section{Conclusion}

We differentiated three acoustic phenotypes present in the release call of Rana temporaria from the Central Pyrenees, as a result of studying the acoustic characteristics vocalization of the pulses instead of the entire call $[35,36]$.

Two acoustic phenotypes corresponded to morphologic male frogs and one to morphologic female frogs. One of the male phenotypes (P2) might be represented by the "pirate" males as a result of the masculinization effect exacerbated by the highest water temperatures found in the glacial lakes. Our study population was acoustically homogeneous and we could not differentiate the occurrence of the clades mentioned in Teacher, et al. [2].

\section{Acknowledgment}

This project was supported by the Animal Anatomy Laboratory Foundation (2013-302). We thank Ursicino Abajo, warden of the Respomuso mountain refuge, for his logistic and gastronomic support, and the field assistant volunteers during the summer courses. We thank the anonymous reviewer for his conscious suggestions which helped improve the manuscript.

\section{References}

1. Gasc JP, Cabela A, Crnobrnja Isailovic J, Dolmen K, Grossenbacher K, et al. (1998) Book review of the
Atlas of Amphibians and Reptiles in Europe. Copeia 4: 1117-118.

2. Teacher AGF, Garner TWJ, Nichols RA (2009) European phylogeography of the common frog (Rana temporaria): routes of postglacial colonization into the British Isles, and evidence for an Irish glacial refugium. Heredity 102: 490-496.

3. Palanca Castan N, Miramontes Sequeiros LC, Palanca Soler A (2019) A Computational Model for the Study of Release Call in the Pyrenean High Mountain European Common Frog (Rana Temporaria). Int J Zoo Animal Biol 2(7): 000169.

4. Vieites DR, Nieto Román S, Barluenga M, Palanca A, Vences M (2004) Post-mating clutch piracy in an amphibian. Nature 431(7006): 305-308.

5. Clutton Brock TH, Parker GA (1995) Sexual coercion in animal societies. Anim Behav 49(5): 1345-1365.

6. Rankin JD, Kokko H (2007) Do males matter? The role of males in population dynamics. Oikos 116(2): 335348.

7. Cotton S, Wedekind C (2009) Population consequences of environmental sex reversal. Conserv Biol 23(1): 196-206.

8. Janzen FJ (1994) Climate change and temperaturedependent sex determination in reptiles. Proc Nat Acad Sci 91(16): 7487-7490.

9. Miller D, Summers J, Silber S (2004) Environmental versus genetic sex determination: a possible factor in dinosaur extinction?. Fertil Steril 81(4): 954-964.

10. Mitchell NJ, Janzen FJ (2010) Temperature-dependent sex determination and contemporary climate change. Sex Devel 4(1-2): 129-140.

11. Grayson KL, Mitchell NJ, Monks JM, Keall SN, Wilson JN, et al. (2014) Sex ratio bias and extinction risk in an isolated population of tuatara (Sphenodon punctatus). PloS one 9(4): e94214.

12. Flament S (2016) Sex Reversal in Amphibians. Sex Devel 10(5-6): 267-278.

13. McCallum ML (2007) Amphibian Decline or Extinction? Current Declines Dwarf Background Extinction Rate. J Herpetol 41(3): 483-491. 


\section{International Journal of Zoology and Animal Biology}

14. Barnosky AD, Matzke N, Tomiya S, Wogan GOU, Swartz B, et al. (2011) Has the Earth's sixth mass extinction already arrived?. Nature 471: 51-57.

15. Davidson C, Williamson CE, Vincent K, Simonich SM, Yip KS, et al. (2013) Anuran population declines occur on an elevational gradient in the western hemisphere. Herpetol Conserv Biol 8(3): 503-518.

16. Savage R (1962) The ecology and life history of the common frog (Rana temporaria temporaria). New York (NY): Hafner Publishing Co.

17. Schmidt RS (1972) Release calling and inflating movements in anurans. Copeia 2: 240-245.

18. Wells KD, Schwartz JJ (2007) The behavioral ecology of anuran communication. In: Narins PM, Feng AS, Fay RR, Popper AN, et al. (Eds.), Hearing and Sound Communication in Amphibians. New York (NY): Springer Handbook of Auditory Research, Springer 28: 44-86.

19. Brzoska J, Walkowiak W, Schneider H (1977) Acoustic communication in the grass frog (Rana t. temporaria L.): calls, auditory thresholds and behavioral responses. J Comp Physiol 118(2): 173-186.

20. Walkowiak W (1980) The coding of auditory signals in the torus semicircularis of the fire-bellied toad and the grass frog-responses to simple stimuli and to conspecific calls. J Comp Physiol 138(2): 131-148.

21. Di Tada IE, Martino A, Sinsch U (2001) Release vocalizations in neotropical toads (Bufo): ecological constraints and phylogenetic implications. J Zool Syst Evol Res 39(1-2): 13-23.

22. Stănescu F, Forti LR, Cogălniceanu D, Márquez R (2018) Release and distress calls in European spadefoot toads, genus Pelobates. Bioacoustics 28: 115.

23. Van Gelder JJ, Evers PMG, Maagnus GJM (1978) Calling and associated behaviour of the Common Frog, Rana temporaria, during breeding. J Animal Ecol 47: 667-676.

24. Morgen A (1957) Die Besonnung und ihre Verminderung durch Horizontbegrenzung. Veroffentl Meteorol Hydrol Dienstes D.D.R. 12: 1-16.

25. Hohenwarter M, Borcherds M, Ancsin G, Bencze B, Blossier M, et al. (2013) GeoGebra 4: 4.
26. Alho JS, Herczeg G, Merilä J (2008) Female biased sex ratios in subarctic common frogs. J Zool 275(1): 5763.

27. Witschi E (1929) Studies on sex differentiation and sex determination in amphibians. III. Rudimentary hermaphroditism and $\mathrm{Y}$ chromosome in Rana temporaria. J Exp Zool 54: 157-223.

28. Hayes TB (1998) Sex determination and primary sex differentiation in amphibians: Genetic and developmental mechanism. J Exp Zool 281: 373-399.

29. Matsuba C, Miura I, Merilä J (2008) Disentangling genetic $v s$. environmental causes of sex determination in the common frog, Rana temporaria. BMC genetics 9: 3.

30. Brelsford A, Rodrigues N, Perrin N (2016) High density linkage maps fail to detect any genetic component to sex determination in a Rana temporaria family. J Evol Biol 29(1): 220-225.

31. Rodrigues N, Vuille Y, Loman J, Perrin N (2015) Sexchromosome differentiation and 'sex races' in the common frog (Rana temporaria). Proc $\mathrm{R}$ Soc 282(1806): 20142726.

32. C atalan J, Pla S, Rieradevall M, Felip M, Ventura M, et al. (2002) Lake Redó ecosystem response to an increasing warming the Pyrenees during the twentieth century. J Paleolim 28(1): 129-145.

33. Pérez Zanón N, Sigró J, Ashcroft L (2017) Temperature and precipitation regional climate series over the central Pyrenees during 1910-2013. Int J Climatol 37: 1922-1937.

34. El Kenawy AM, López-Moreno JI, Vicente Serrano SM (2011) Recent trends in daily temperature extremes over northeastern Spain (1960-2006). Nat Hazards Earth Syst Sci 11(9): 2583-2603.

35. Matar M, Welti R (2009) Capturing the physics of Helmholtz resonators with the acoustic wave equation. Lat Am J Phys Educ 3: 127-134.

36. Palanca-Soler A, Vieites DR, Martínez MS (1995) Contribución al estudio anatómico del género Rana L., 1758 en el Alto Aragón. Lucas Mallada 7: 227-247.

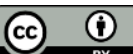

